\title{
Pharmacovigilance of Biologics in a Multisource Environment
}

\author{
Sreedhar Sagi, PhD; Hillel P. Cohen, PhD; and Gillian R. Woollett, MA, DPhil
}

\begin{abstract}
SUMMARY
It is important that systems are in place to ensure that appropriate and comprehensive records are kept for use of all medications. It is fundamental to an effective pharmacovigilance system that patient medical records contain sufficient information to identify which medication has been prescribed, when it was administered, and at what dose. The availability of biologics from multiple sponsors has raised questions by some health care providers about the ability of current pharmacovigilance systems to trace specific biologics.

In this article, periodic safety update reports were used to assess current postapproval safety monitoring for 3 biosimilars (epoetin alfa, somatropin, and filgrastim) that collectively represented nearly 350 million patient days of treatment worldwide. The reference products have each been marketed for over 10 years, forming a strong baseline of postmarketing safety data against which the safety of biosimilars can be compared. Published data from Denmark were also reviewed as additional evidence of how current pharmacovigilance systems are able to attribute adverse events to particular medicines. Collectively, the data show that spontaneous adverse drug reactions are reported by brand name in the majority of cases and are attributable to a specific medicine. Also discussed are the informational elements critical to monitoring biologics, or indeed any medicine, to ensure the availability of complete information so medicines that a patient has received can be quickly identified should a safety event occur.

We support the addition of a single data element, the batch/lot number, to enhance the value of current pharmacovigilance systems. Adoption of 2-D barcodes in the European Union (EU) and standardized numerical identifiers in the United States addresses this need, since they include batch/ lot numbers. These identifiers are already being implemented in the United States and the EU to improve patient safety, reduce medication errors, facilitate anticounterfeiting, and enable effective product recalls and adverse event reporting. Importantly, electronic identifiers will ameliorate safety reporting concerns with respect to biosimilars, while concurrently achieving these much broader public health objectives through more complete pharmacovigilance data.
\end{abstract}

J Manag Care Spec Pharm. 2017;23(12):1249-54

Copyright $\odot 2017$, Academy of Managed Care Pharmacy. All rights reserved.

$\mathrm{P}$ atient records are a critical source of information as to how medicines approved in highly regulated markets perform in real-world clinical settings, especially in patients who have comorbidities and may be taking multiple medications and who may have less than ideal compliance. Patient records contribute to statistically meaningful datasets for population-based decision making and capture information on rare events that are impossible to ascertain before approval. When well curated, these data can support the development of the medicine label, as new conclusions become available based on postmarketing observations, thereby optimizing use by health care providers. Patient safety reports offer broad information on the effective and safe use of medicines across multiple markets. ${ }^{1}$ Because the data are cumulative and can be assembled in a manner suitable for examination over time, they can be used to answer research questions not anticipated at initial approval. ${ }^{2}$

\section{Core Pharmacovigilance Issues}

Countries with highly regulated health care markets, such as the United States, the European Union [EU], and Japan, have developed largely consistent expectations for medical records, from which data can be pooled and analyzed in order to support pharmacovigilance analyses (albeit privacy and security constraints remain locally regulated $\left.{ }^{3}\right) .{ }^{4}$ While pharmacovigilance systems applied to all medicines are fundamentally the same, ${ }^{5}$ these systems can be used to address the uncertainties that have been voiced regarding products of the nascent biosimilar industry, including discrimination between biologics that contain "essentially the same" active ingredients and whether switches between biological medicines from different sponsors that are "essentially the same" affect clinical outcomes for individual patients. ${ }^{6}$ These questions can be equally applied to assessing whether there are clinically relevant differences in outcomes when comparing different batches/lots of a single medication from the same sponsor, especially after manufacturing changes. ${ }^{7,8}$ Consequently, how all biologics are identified throughout their life cycle of use is subject to much discussion. ${ }^{9-13}$

It has been suggested that multiple sources (different sponsors, different sites from the same sponsor, or changes in either over time) of a given biologic will put patients at greater risk than is the case when only a single source of the biologic is available. To investigate this premise, we examined periodic safety update reports (PSURs) to determine if evidence exists to suggest any such safety concerns, as well as to determine how established naming conventions are used in practice. ${ }^{14}$ PSURs "present a comprehensive, concise and critical analysis of the benefit/risk balance of the medicinal product taking into account new or emerging information in the context of the cumulative information on the risks and benefits." ${ }^{15}$

\section{Naming Conventions}

For context, the European Medicines Agency (EMA) uses established international naming conventions to track biologics and drugs. It captures the brand name (trademarked to a sponsor), international nonproprietary name (INN; as issued and administered by the World Health Organization ${ }^{16}$ ), and 
TABLE 1 Safety Monitoring Experience with 3 Biosimilars with Total Patient Days of Treatment After Approval

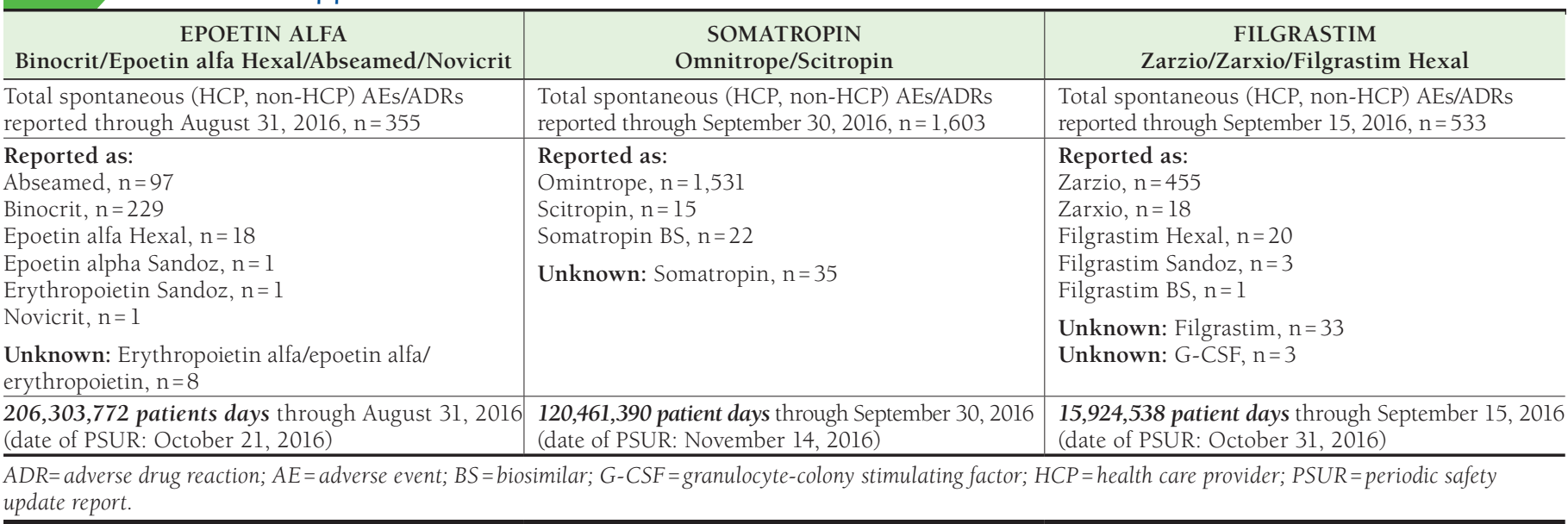

manufacturer/sponsor (the holder of the medicinal product approval/license). Consequently, a medicine has 1 INN worldwide.

Meanwhile, in the United States, the United States Adopted Names (USAN) usually match the INN. ${ }^{17}$ However, the U.S. Food and Drug Administration (FDA) has issued final guidance that breaks with the international nonproprietary naming conventions for biologics only. The FDA adds a 4-letter suffix to the USAN/INN to create the U.S. proper name. ${ }^{18}$ The intention is to apply this type of suffix to all biologics and will be applied retroactively. However, to date, the FDA has only issued these unique nonproprietary names for biosimilars and not for newly approved or already licensed originator biologics. In addition, the 77 other biologics approved by the FDA that share 25 nonproprietary names have yet to be renamed. ${ }^{19}$ In the interest of clarity, we use the term "nonproprietary name" here to encompass all nonproprietary names (e.g., INN, USAN, generic name, and proper name) for all medicines.

\section{Sample Assessment of Pharmacovigilance Data for Biosimilars}

We examined the frequency and thoroughness of how current pharmacovigilance systems attribute adverse events to biologics, including particular biosimilars, and whether a significant number of PSUR-reported events could be assigned. In our analysis, we also sought to find the most effective data element recorded that enabled immediate attribution of an adverse event to a specific medicine-the primary concern for effective pharmacovigilance. As we show here, the evidence does not suggest any inadequacy with the current pharmacovigilance system in operation. However, the addition of batch/lot numbers could be valuable for pharmacovigilance purposes.

We examined records representing nearly 350 million patient days of treatment with Sandoz biosimilars to the reference biologics Genotropin (somatropin), Eprex (epoetin alfa), and Neupogen (filgrastim). ${ }^{20}$ The analysis was limited to the review of primary data that were available and comprised data contained in the Sandoz postmarketing safety databases. In some cases, there were also multiple other brand-name medicines available in the same markets that contained the same or closely related active pharmaceutical ingredients (API), as well as other biosimilars. The Sandoz pharmacovigilance databases offered a unique opportunity to evaluate pharmacovigilance capabilities related to product names because multiple brand names were used for the same product in different markets, but the results were collected into a single database. This practice removed potential variability in safety reporting because of differences inherent in databases or variability in product quality. While the Sandoz biosimilars are single-sourced products with multiple brand names, they served as effective surrogates for multisourced biologics and provided meaningful data in an internally controlled setting.

Then, we examined the available PSURs. All spontaneous adverse drug reaction (ADR) reports collected from the Sandoz proprietary safety databases for the period from initial approval to the respective PSUR data lock point were extracted. ${ }^{14}$ Reports that represented literature and clinical trial reports were excluded. The regulatory pathway used to approve a specific medicine (e.g., originator or biosimilar) was not considered as part of the analysis. A secondary review step ensured that any data entry errors caused by the original search's failure to capture the brand name (e.g., the brand name was not entered accurately or in the right data field) were rectified. The cumulative data were grouped by brand names or, if that was not possible, were labeled as unknown.

To supplement the analysis, we also reviewed publicly available information on the use of biologics from the "Danish Pharmacovigilance Update" provided by the Danish Medicines Agency, whichincluded the more complexinfliximab-containing biosimilars. 


\section{FIGURE 1 Comparing Products for Pharmacovigilance Purposes Using Different Available Data Fields}

\section{Group}

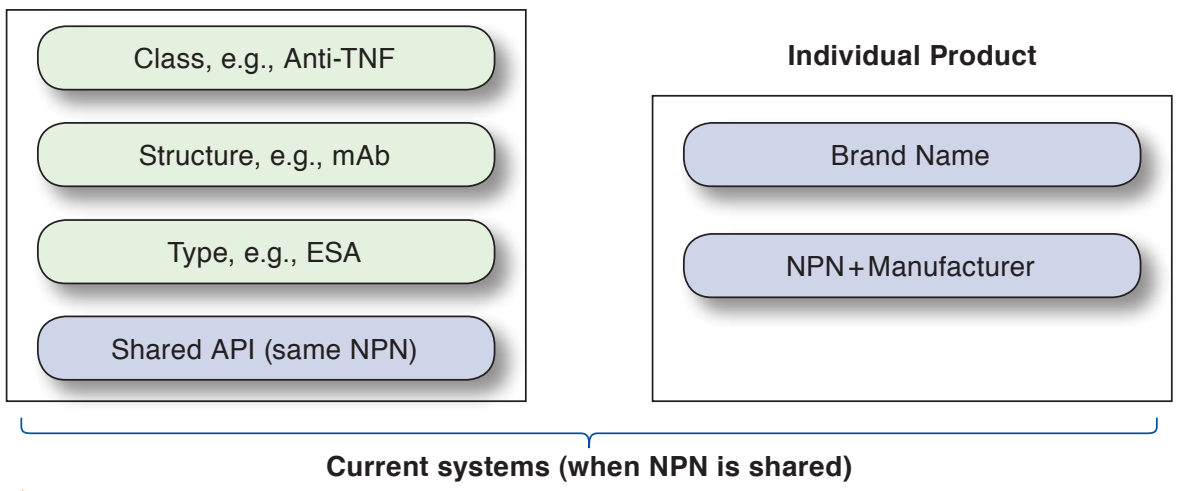

Batch/Lot

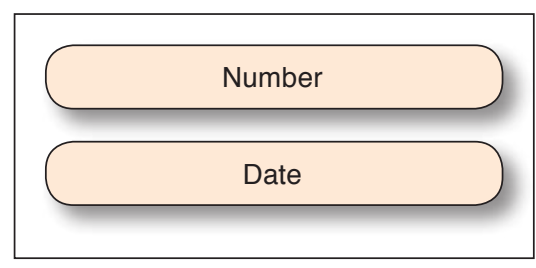

Achieved with 2-D barcode (EU) and digital standardized numerical identifier (United States)

API = active pharmaceutical ingredients; ESA = erythropoiesis-stimulating agent; EU = European Union; mAb=monoclonal antibody; NPN = nonproprietary name; TNF= tumor necrosis factor.

Table 1 provides data on Sandoz-sponsored biosimilars containing epoetin alfa, somatropin, and filgrastim from their dates of approval and/or launch through the fall of 2016. Depending on the product, data were available for 6 to over 10 years. The medicines were marketed with more than 1 brand name but shared nonproprietary names and were based on the same EMA evaluation and approval (with the exception of Zarxio in the United States). ${ }^{21}$ Those medications are as follows:

- Abseamed/Binocrit/Epoetin Alfa Hexal (epoetin alfa), EU approval date August 28, 2007

- Omnitrope/Scitropin (somatropin), EU approval date April 12, 2006

- Filgrastim Hexal/Zarzio (filgrastim), EU approval date February 6, 2009; Zarxio (filgrastim-sndz) U.S. approval March 6, $2015^{22}$

That the same medicines have multiple brand names is an additional test of the current pharmacovigilance system's ability to track medicine use. More than 1 brand name for the same medicine is common in the $\mathrm{EU}$, and while less common in the United States, it still does occur.

As seen in Table 1, spontaneous ADRs are reported by brand name in the vast majority of cases. There is no evidence that the nonproprietary name alone is a common identifier nor a source of confusion. In addition, there is no evidence that a more complicated molecule has more ADRs, even though epoetin is generally regarded as a more complicated molecule than filgrastim or somatropin. The data in Table 1 show a consistency across the PSURs that were examined.

We also searched recent literature for infliximab, a monoclonal antibody for which biosimilars are available. As with the medicines already discussed, the same infliximab biosimilar is marketed under more than 1 brand name: Remsima/ Inflectra (infliximab), EU approval date September 10, 2013. ${ }^{21}$

Danish national pharmacovigilance data show a total of 132 reports of suspected ADRs in 2015 for biologics containing somatropin ( 2 ADRs), filgrastim (2), follitropin alfa (3), and infliximab (Remsima 64, Remicade 55, no brand name 6). The 6 cases where the brand name was not provided were all literature cases. Similar to the Sandoz biosimilar data, the Danish data show that ADRs were reported by brand name in nearly all cases. ${ }^{15}$ According to the February 2016 Danish report, "The vast majority of the suspected adverse reactions reported in relation to the use of the described biological medicines and biosimilars are known adverse reactions described in the summaries of product characteristics. Based on the ADR reports received in 2015, there is nothing to suggest that the risk profiles of the biosimilar medicinal products are any different from those of their reference products." 15 The Danish report represented a national dataset and also included infliximab products, whereas our data were for 3 products used worldwide; however, the same conclusions were reached.

\section{What Do These Results Mean for Pharmacovigilance} of Biologics in a Multisource Environment?

It has also been suggested that brand names are insufficient for biologic pharmacovigilance purposes, when biosimilars are available. This suggestion is apparently based on the experience with generic drugs, but it may be an erroneous comparison, since generic drugs rarely have brand names. ${ }^{23}$ To date, the majority of biologics in highly regulated markets, including all approved U.S. biosimilars, have unique brand names (although 
not mandatory as in the EU). Many currently licensed originator biologics in the United States have shared nonproprietary names for decades with no pharmacovigilance concerns, ${ }^{19}$ and these names are the same nonproprietary names that are shared around the world (indeed the only exception to shared nonproprietary names for biologics are U.S. biosimilars ${ }^{18}$ ). Consequently, we have a mechanism to group medicines based on shared API and another mechanism to distinguish them based on brand name. Furthermore, the combination of "nonproprietary name+manufacturer" is unique to each specific biologic (Figure 1). Importantly, the current system is entirely independent of the regulatory pathway by which any medicine is approved.

Nonetheless, a complete pharmacovigilance system can benefit from records that include batch/lot numbers. ${ }^{24}$ The inclusion of these numbers allows any issue that relates to a specific batch/lot to be detected and captured more rapidly. For biologics, where use of comparability in support of manufacturing changes has an exemplary safety record, ${ }^{7,25}$ there are, nonetheless, occasional instances where manufacturing changes have led to changes in clinical outcomes. ${ }^{8}$ The batch/lot number of an administered biologic can be recorded by health care providers (e.g., as is already done with vaccines) or by the pharmacist when dispensed to the patient. The inclusion of the batch/lot number is also supported by the August 2016 "Danish Pharmacovigilance Update." ${ }^{24}$ In fact, such an approach is already being implemented in the United States and the EU.

Concerns with the fidelity of drug supply chains, including the increasing challenges with counterfeit medicines, have led the EU to develop systems for 2-D barcoding on medicines and real-time electronic capture of information. ${ }^{26-28}$ The 2-D barcode is affixed to pharmacy packaging materials; is machine-readable; and has additional capabilities to improve patient safety, reduce medication errors, facilitate anticounterfeiting, and enable effective medicine recalls and adverse event reporting.

The United States is pursuing a similar initiative to ensure better control and inventory management throughout the supply chain with the use of a standardized numerical identifier (SNI) ${ }^{29}$ Changes in the law precipitated this initiative, ${ }^{30}$ and it is "to be applied to a prescription drug at the point of manufacturing and repackaging at the package- or pallet-level, sufficient to facilitate the identification, validation, authentication, and tracking and tracing of the prescription drug." Further, the statute requires that "to the extent practicable, the SNI should be harmonized with international consensus standards for such an identifier." 30

We believe that the most valuable enhancement to any pharmacovigilance system is the reliable inclusion of batch/ lot numbers in addition to brand name, nonproprietary name, and manufacturer. In highly regulated markets, all approved biosimilars have been given brand names in the same manner as originator biologics. In those countries where brand names are not available, the combination of nonproprietary name and manufacturer will serve the same purpose of uniquely identifying a given medicine.

\section{A Proposal for More Effective Global Pharmacovigilance}

Current pharmacovigilance systems contain sufficient elements to ensure patient safety. However, implementation and verification of data entry are critical to pharmacovigilance. No system can compensate for a failure to enter and maintain complete records. Since handwritten submissions have inherent limitations, electronic systems are preferable.

Capture of the batch/lot number as a routine component of safety reporting offers a significant improvement in pharmacovigilance with no disruption to current approaches. The inclusion of the batch/lot number allows current systems to group medicines by 3 distinct attributes: (1) shared attributes-API is the most obvious and important attribute (Figure 1, left column); (2) specific medicines by brand name or manufacturer+nonproprietary name (Figure 1, middle column); and (3) specific batch/lot number of a specific individual medicine (Figure 1, right column).

These 3 attributes have specific and different values for pharmacovigilance purposes and have the potential to reveal unique and meaningful safety signals that can facilitate decisions that ensure the safety of patients but also minimize unnecessary restrictions for patients who are otherwise benefiting from the medication (e.g., by allowing single batch recalls). These attributes allow maximal pooling of data in a manner that can lead to more timely decisions. For instance, the loss of the ability to group all medicines with a shared API would mean that the rarest signals would likely be detected much later, if at all.

With machine-readable 2-D barcodes, the EU is already well into the development of an automatable option that can carry additional capabilities over and above those necessary for pharmacovigilance as traditionally conducted by using PSURs Where available, 2-D barcodes can be used to capture batch/lot numbers for pharmacovigilance purposes. The codes can allow tracing to individual batch/lots, which allows correlation to simple batch-to-batch variation, changes in the manufacturing, or other aspects in the supply chain for all biologics.

\section{Current Pharmacovigilance Systems Work But Can Be Improved} Specific information, collected in a consistent manner, is critical to the monitoring of any biologic, or indeed any drug, such that complete information is available to immediately identify the medicines that a patient has received should an adverse event occur. It is also important to only change current systems when there is a clear value to patients in doing so. 
In the EU, there are already many biologics to which biosimilars are now available, and there are numerous examples of multiple biosimilars approved for the same reference product. In examining the data, we did not find evidence of current pharmacovigilance systems being confounded by the availability of biosimilars, in part because all such medicines to date have brand names. However, even without brand names, the nonproprietary name + manufacturer data elements will always uniquely identify any given medicine and, at the same time, create a verification cross-check for those medicines that have brand names.

We support the inclusion of batch/lot numbers in the patient record, an enhancement that is already being captured as part of the EU 2-D barcoding system and the U.S. SNIs. ${ }^{31,32}$ The inclusion of these numbers is a way to expedite resolution of situations such as that with Eprex in the early 2000s, where a manufacturing change led to a safety risk for patients. ${ }^{8}$ However, this situation involved a rare adverse event that was only spotted with a metadata analysis. Such rare events are always going to be difficult to detect; however, the broader value of capturing batch/lot numbers is evident.

\section{Conclusions}

We expect brand names to remain the most frequently and reliable recorded data element for any medicine but find that the most valuable enhancement to any pharmacovigilance system is the consistent inclusion of batch/lot numbers in addition to brand names, nonproprietary names, and names of manufacturers.

\section{Authors}

SREEDHAR SAGI, PhD, Sandoz Biopharmaceuticals, Singapore, and HILLEL P. COHEN, PhD, Sandoz, Princeton, New Jersey. GILLIAN R. WOOLLETT, MA, DPhil, Avalere Health, Washington, DC.

AUTHOR CORRESPONDENCE: Gillian R. Woollett, MA, DPhil, Avalere Health, 1350 Connecticut Ave., N.W., \#900, Washington, DC 20036. Tel.: 202.207.1320; E-mail: gwoollett@avalere.com.

\section{DISCLOSURES}

This work was funded by Sandoz, a Novartis division. The authors were fully responsible for the content, editorial decisions, and opinions expressed in this article. No author received an honorarium related to the development of this manuscript. Sagi and Cohen are employees of Sandoz, and Woollett is an employee of Avalere Health.

Study concept and design were contributed by Sagi and Woollett, along with Cohen. Data were primarily collected by Sagi, along with Woollett, and data interpretation was provided by all the authors. The manuscript was written by Woollett, along with Sagi and Cohen, and revised by Sagi and Cohen, along with Woollett.

\section{REFERENCES}

1. International Conference on Harmonisation of Technical Requirements for Registration of Pharmaceuticals for Human Use. ICH Harmonised Tripartite Guideline. Periodic benefit-risk evaluation report (PBRER) E2C(R2). Current step 4 version. December 17, 2012. Available at: http:// www.ich.org/fileadmin/Public_Web_Site/ICH_Products/Guidelines/ Efficacy/E2C/E2C_R2_Step4.pdf. Accessed November 7, 2017.

2. U.S. Food and Drug Administration. FDA's Sentinel initiative. December 14, 2016. Available at: https://www.fda.gov/Safety/FDAsSentinelInitiative/ default.htm. Accessed November 7, 2017.

3. U.S. Department of Health \& Human Services. Summary of the HIPAA Privacy Rule. Available at: https://www.hhs.gov/hipaa/for-professionals/privacy/laws-regulations/index.html. Accessed November 7, 2017.

4. European Medicines Agency. Explanatory note to GVP Module VII EMA/102307/2017. March 23, 2017. Available at: http://www.ema.europa.eu/ docs/en_GB/document_library/Scientific_guideline/2017/04/WC500225264 pdf. Accessed November 7, 2017.

5. International Conference on Harmonisation of Technical Requirements for Registration of Pharmaceuticals for Human Use. Efficacy guidelines. E2A-E2F Pharmacovigilance. Available at: http://www.ich.org/products/guidelines/efficacy/article/efficacy-guidelines.html. Accessed November 7, 2017.

6. European Medicines Agency. Biosimilar medicines. Available at: http://www. ema.europa.eu/ema//index.jsp?curl=pages/medicines/general/general_content_001832.jsp\&mid=WC0b0lac0580bb8fda. Accessed November 7, 2017.

7. U.S. Food and Drug Administration. Guidance for industry. Q5E comparability of biotechnological/biological products subject to changes in their manufacturing process. June 2005. Available at: https://www.fda.gov/ downloads/Drugs/GuidanceComplianceRegulatoryInformation/Guidances/ UCM073476.pdf. Accessed November 7, 2017.

8. Casadevall N, Nataf J, Viron B, et al. Pure red-cell aplasia and antierythropoietin antibodies in patients treated with recombinant erythropoietin. N Engl J Med. 2002;346(7):469-75. Available at: http://www.nejm.org/doi/ full/10.1056/NEJMoa011931. Accessed November 7, 2017.

9. World Health Organization. Guidance on INN. Available at: http://www. who.int/medicines/services/inn/innquidance/en/. Accessed November 7, 2017.

10. World Health Organization. Biologics qualifier. Available at: http://www. who.int/medicines/services/inn/inn_bio_bq/en/. Accessed November 7, 2017.

11. World Health Organization. Report on the expert consultation on improving access to and use of similar biotherapeutic products. Presented at: International Labour Organization; Geneva, Switzerland; May 2-3, 2017. Available at: http://www.who.int/medicines/access/biotherapeutics/FINAL_ Report-improving-access-to-and-use-of-biotherapeutics_October2017.pdf. Accessed November 7, 2017.

12. U.S. Food and Drug Administration. U.S. FDA considerations: discussion by national regulatory authorities with World Health Organization (WHO) on possible International Non-Proprietary Name (INN) policies for biosimilars. September 1, 2006. Available at: http://www.fda.gov/Drugs/ DevelopmentApprovalProcess/HowDrugsareDevelopedandApproved/ ApprovalApplications/TherapeuticBiologicApplications/Biosimilars/ ucm 375086.htm. Accessed November 7, 2017.

13. Regulations.gov. Nonproprietary naming of biological products. Docket folder summary. Docket ID: FDA-2013-D-1543. Available at: https://www. regulations.gov/docket?D=FDA-2013-D-1543. Accessed November 7, 2017.

14. European Medicines Agency. Guideline on good pharmacovigilance practices (GVP). Module VI-Management and reporting of adverse reactions to medicinal 4 products (rev 1). EMA/873138/2011 Rev 1*. June 6, 2013. Available at: http://www.ema.europa.eu/docs/en_GB/document_library/ Scientific_guideline/2013/06/WC500144009.pdf. Accessed November 7, 2017. 
15. Danish Medicines Agency. Special focus on reported adverse reactions to biological medicines and biosimilars. Danish Pharmacovigilance Update. Vol. 7, No. 2. February 2016. Available at: https://laegemiddelstyrelsen.dk/ en/news/2016/danish-pharmacovigilance-update,-february-2016/ /media/ FF5865ABAC6D492AB650739216D65DCB.ashx. Accessed November 7, 2017.

16. World Health Organization. International Nonproprietary Names. Available at: http://www.who.int/medicines/services/inn/en/. Accessed November 7, 2017.

17. American Medical Association. USAN Council. Available at: https:// www.ama-assn.org/about-us/usan-council. Accessed November 7, 2017.

18. U.S. Food and Drug Administration. Nonproprietary naming of biological products. Guidance for industry. January 2017. Available at: http://www. fda.gov/downloads/Drugs/GuidanceComplianceRegulatoryInformation/ Guidances/UCM459987.pdf. Accessed November 7, 2017.

19. McCamish M, Gallaher A, Orloff J. Biosimilar by name and biosimilar by nature. Table 1. The RPM Report. July/August 2013. Available at: https:// www.sandoz.com/sites/www.sandoz.com/files/rpm-report.pdf. Accessed November 7, 2017

20. Regulations.gov. Novartis (Sandoz) comment on FDA notice: nonproprietary naming of biological products; draft guidance; availability. Docket ID: FDA-2013-D-1543-0172. October 30, 2015. Available at: https:// www.regulations.gov/document?D=FDA-2013-D-1543-0172. Accessed November 7, 2017

21. European Medicines Agency. Public assessment reports for biosimilars. Available at: http://www.ema.europa.eu/ema/index.jsp?curl=pages\%2Fmedic ines\%2Flanding\%2Fepar_search.jsp\&mid=WC0b0lac058001d124\&searchT $\mathrm{ab}=$ searchByAuthType $\&$ alreadyLoaded $=$ true $\&$ is NewQuery=true\&status=Aut horised\&keyword=Enter+keywords\&searchType=name\&taxonomyPath=\&tr eeNumber=\&searchGenericType=biosimilars. Accessed November 7, 2017.

22. U.S. Food and Drug Administration. Approval letter for Zarxio (filgrastim-sndz). Reference ID: 3711895. Available at: https://www.accessdata. fda.gov/drugsatfda_docs/appletter/2015/125553Origls000ltr.pdf. Accessed November 7, 2017.

23. Lietzan EF, Sim LE, Alexander EA. Biosimilar naming: how do adverse event reporting data support the need for distinct nonproprietary names for biosimilars? Food and Drug Law Institute's Food and Drug Policy Forum. 2013;3:1-20.
24. Danish Medicines Agency. Focus on reported adverse reactions to biological medicines. Danish Pharmacovigilance Update. Vol. 7, No. 7. August 2016. Available at: https://laegemiddelstyrelsen.dk/en/news/2016/ /media/ CDD5B752B71D4F08AE70C8DAA505F7D3.ashx. Accessed November 7, 2017

25. European Medicines Agency. Guideline on good pharmacovigilance practices (GVP). Product- or population-specific considerations II: biological medicinal products. EMA/168402/2014 Corr*. August 4, 2016. Available at: http://www.ema.europa.eu/docs/en_GB/document_library/Scientific_guideline/2016/08/WC500211728.pdf. Accessed November 7, 2017.

26. Eur-Lex. EU 2-D barcode: Commission Delegated Regulation (EU) 2016/161 of 2 October 2015 supplementing Directive 2001/83/EC of the European Parliament and of the Council. Available at: http://eur-lex. europa.eu/legal-content/EN/TXT/?uri=uriserv:OJ.L_.2016.032.01.0001.01. ENG\&toc=OJ:L:2016:032:TOC. Accessed November 7, 2017.

27. European Commission. New safety features to protect EU consumers from falsified medicines. Press release. February 9, 2016. Available at: http:// ec.europa.eu/dgs/health_food-safety/dyna/enews/enews.cfm?al_id=1665. Accessed November 7, 2017.

28. European Medicines Agency. Measures to help protect patients from falsified medicines. Press release. February 9, 2016. Available at: http://www ema.europa.eu/ema/index.jsp?curl=pages/news_and_events/news/2016/02/ news_detail_002467.jsp\&mid=WC0b01ac058004d5cl. Accessed November 7, 2017.

29. U.S. Food and Drug Administration. Guidance for industry. Standards for securing the drug supply chain-standardized numerical identification for prescription drug packages. March 2010. Available at: https://www. fda.gov/downloads/RegulatoryInformation/Guidances/UCM206075.pdf. Accessed November 7, 2017.

30. U.S. Food and Drug Administration. Implementation of Drug Supply Chain Security Act (DSCSA). Available at: https://www. fda.gov/Drugs/DrugSafety/DrugIntegrityandSupplyChainSecurity/ DrugSupplyChainSecurityAct/. Accessed November 7, 2017.

31. European Medicines Agency and U.S. Food and Drug Administration. Guiding principles for the international pharmacovigilance cluster. May 22, 2015. Available at: https://www.fda.gov/downloads/internationalprograms/ partnerships/ucm454588.pdf. Accessed November 7, 2017.

32. U.S. Food and Drug Administration. Improving efficiency and rigor of pharmacovigilance at FDA. Available at: https://www.fda.gov/scienceresearch/specialtopics/regulatoryscience/ucm529585.htm. Accessed November 7, 2017. 